\title{
Performance Evaluation of a Double-Glazed Box-Type Solar Oven with Reflector
}

\author{
Joshua Folaranmi \\ Department of Mechanical Engineering, Federal University of Technology, Niger State, Minna, Nigeria \\ Correspondence should be addressed to Joshua Folaranmi; folajo2008@yahoo.com
}

Received 28 November 2012; Revised 30 March 2013; Accepted 9 April 2013

Academic Editor: Jayanta Deb Mondol

Copyright (C) 2013 Joshua Folaranmi. This is an open access article distributed under the Creative Commons Attribution License, which permits unrestricted use, distribution, and reproduction in any medium, provided the original work is properly cited.

This research paper describes the performance evaluation of a double-glazed box-type solar oven with reflector fabricated using locally available materials, compressed sawdust with binder; size of the box is $700 \mathrm{~mm} \times 700 \mathrm{~mm} \times 400 \mathrm{~mm}$ and $10 \mathrm{~mm}$ thickness. The experimental solar cooker consists of an aluminium absorber plate $(1 \mathrm{~mm})$ painted matt black and a double-glazed lid. The bottom and sides are lagged with fibreglass wool insulator, thickness $=50 \mathrm{~mm}, k=0.052 \mathrm{~W} / \mathrm{m}^{\circ} \mathrm{C}$. The reflector consists of a woodenframed commercially available specular plane mirror which is sized to form a cover for the box when not being in use. Its thermal performance was tested according to the ASAE International Test procedure and Bureau of Indian Standards (BIS) for testing the thermal performance of box-type solar cooker. Thermal performance experiments were conducted in order to determine the first figure of merit $\left(F_{1}\right)$, the second figure of merit $\left(F_{2}\right)$ and standard cooking power $\left(P_{s}\right)$. The obtained test results were employed to calculate the two figures of merit $\left(F_{1}\right.$, and $\left.F_{2}\right)$ and the standard cooking power $\left(P_{50}\right)$ to be $0.11 \mathrm{Km}^{2} \mathrm{w}^{-1}, 0.31$, and $23.95 \mathrm{~W}$, respectively. Finally, the results illustrated that the cooker has a good reliability for cooking food and boiling water.

\section{Introduction}

From time immemorial, fire has been used for cooking food to make it palatable and digestible. In ancient times, in the villages, there was no scarcity of fuel, and hence, not much attention was given to minimize the loss of energy while using wood for cooking. Almost invariably, open fire was used for transferring the heat energy to the food from the source of the fuel and this accounted for a large percentage of heat lost to the surroundings. Unfortunately, up to the present day, where gas cooker or electric stove is used, the problem of heat loss to the surrounding still exists. It is for this reason that very high amount of fuel is needed for cooking, so that enough heat is available for cooking of food inspite of considerable loss of heat from the source of fuel: wood, coal, gas, or electricity. The main sources of power generation today are fossil fuels (oil, gas, and coal), nuclear reaction, and hydro energy is also used. These are depletable, nonrenewable and pollute the environment. The hydro energy does not produce adequate and consistent power for the nation's consumption [1]. Moreover, the high cost of exploration techniques and the devaluation of the currency of a developing country like
Nigeria have made the power from fossil fuel unaffordable for most people [2].

Two million households depend on wood and charcoal to prepare food and worldwide supply of wood is rapidly disappearing [3]. The demands of massive population growth and the inefficient conversion of wood to charnel have outstripped much of the world's forests ability to regenerate, creating a phenomenon known as deforestation. Deforestation is the gravest environmental crisis facing the world today; its far reaching effects include the following.

(i) The decreasing availability of firewood.

(ii) Removing the trees from an area is to remove its source of life (deforestation has left more than $25 \%$ of the African Continent almost useless for cultivation).

(iii) Forest protects the soil against erosion and reduces the risk of landslides and vacancies.

(iv) Forest increases the rate that rain water recharges ground water as well as controls the rate that water is released in watersheds, helping to sustain fresh water supplies. 
(v) Forest affects the climate. The occurrence and strength of floods and droughts increase when they are criminated.

(vi) Forest is an important source of oxygen.

(vii) Forest stores large amounts of carbondioxide that are released when trees are cut or burned [4].

Wood stubble and grass are used in about half of the world's households as energy for cooking and heating. In most parts of the developing world, they are burned in open fires or inefficient stoves with less air in kitchens with little or no ventilation leading to incomplete combustion and production of poisonous gases such as carbon monoxide. Biomass smoke has many harmful effects such as: acute respiratory infection (respiratory infections alone cause between four and five million deaths per year among children), pneumonia, tuberculosis, cancer, lower birth weights, cataract, nervous and muscular fatigue [5]. One alternative is to use kerosene, gasoline, or liquefied petroleum gas, but transportation and production of these energy sources make it expensive to common man in remote villages where the demands are very high and incessant. Another alternative is to use pressure cookers, where heat loss through steam escaping from food materials is controlled to a great extent [6]. The house wife using the pressure cooker realizes how much saving in time and fuel is achieved due to the use of this ingenious device. However, this is still not being used in rural areas, and even in urban areas it is not used extensively because it is beyond the reach of the common man. The next obvious alternative available is to use solar energy from the sun to heat and cook our food, particularly in equatorial regions where solar energy is abundant. The box-type solar oven is capable of cooking food from direct solar rays without any concentration. Briefly, the box-type solar oven consists of a compressed sawdust frame box having its inside lined with tray-inner cooker box-aluminium sheet is $1 \mathrm{~mm}$ thick, painted black with the gap between the compressed sawdust frame and the tray-inner cooker box being filled with fibre glass. The whole assembly is covered with two $4 \mathrm{~mm}$ thick glasses at a distance of $40 \mathrm{~mm}$ from each other, which could be slide in and out along the length of the box in order to open and close the oven. It works by trapping and converting the solar power from the rays that enter through the two glasses that cover the wooden box in which the cooking pot is placed to heat energy for cooking. The mechanism behind this phenomenon is that the accumulated solar energy absorbed by the absorber inside the box and reabsorbed by the cooking pot is not allowed to escape as in the case of other cooking methods; this raises the temperature of the space inside the box to above $100^{\circ} \mathrm{C}$, which is sufficient to boil and cook the food. The steam generated from the food is reabsorbed inside the food material together with its latent heat and is utilized fully for the most efficient means of cooking as far as the utilization of heat is concerned. The main advantages of box-type solar oven are the following. It uses both direct and diffuse radiation, requires little intervention by the user, is very easy and safe to use, is easy to construct, has high acceptance angle (angle through which the sun's image remains on the absorber), has high tolerance for tracking error. The objectives of the research paper are:

(i) to fabricate box-type solar cooker with double glasses and one reflector;

(ii) to experimentally evaluate the thermal performance of the box-type solar oven over varying atmospheric conditions using the following: (i) first figure of merit, (ii) second figure of merit, and (iii) cooking power.

\section{Description of Parts}

The box-type solar oven is made up of two main parts, namely,

(i) the flat-plate collector and

(ii) the reflector.

2.1. The Flat-Plate Collector. Essentially, the flat-plate collector consists of the following elements.

Absorber Plate. This is the oven floor which is painted black; it is the part that collects the sunlight and converts it to heat being a blackbody. It is made of Aluminium sheet.

Glazing. This is the material which covers the absorber plate and allows sunshine to reach the absorber plate while preventing rain, wind, and cold from reaching the plate surface that will cause loss of heat. It is referred to as "lower case", and it forms the lid or cover of the solar oven.

Casing. The whole assembly of the collector components is contained within a container referred to as the "lower case" which is made of compressed sawdust with suitable binders instead of plywood in order to reduce heat loss.

Insulator. This is used to minimize heat loss from the system. It is placed under the absorber plate. The insulator must be able to withstand stagnation temperature, should be heat resistant and not subjected to outgassing, and should not be damageable by moisture or insects. Insulating materials are usually fibre glass, mineral wool, Styrofoam, and urethanes. Because of their stability at higher temperatures, fibre glass and mineral wool are better than Styrofoam and urethane. Some urethanes will deform at high temperatures, while others give off toxic gases and may even burst into flames [7]. For this design fibre glass is used as insulator under the absorber plate, and the gap between the tray and the box is also filled with fibreglass wool insulator.

2.2. Reflector. This is a plane mirror fixed to the lid of the cooker cover to direct more heat from the sun into the cooker. The box-type solar oven is shown in Figure 1.

\section{Experimental Solar Cooker Details}

\subsection{Design Specifications. They include the following:}

(i) outer box, compressed sawdust of $10 \mathrm{~mm},(700 \times 700$ $\times 400 \mathrm{~mm}$ ); 


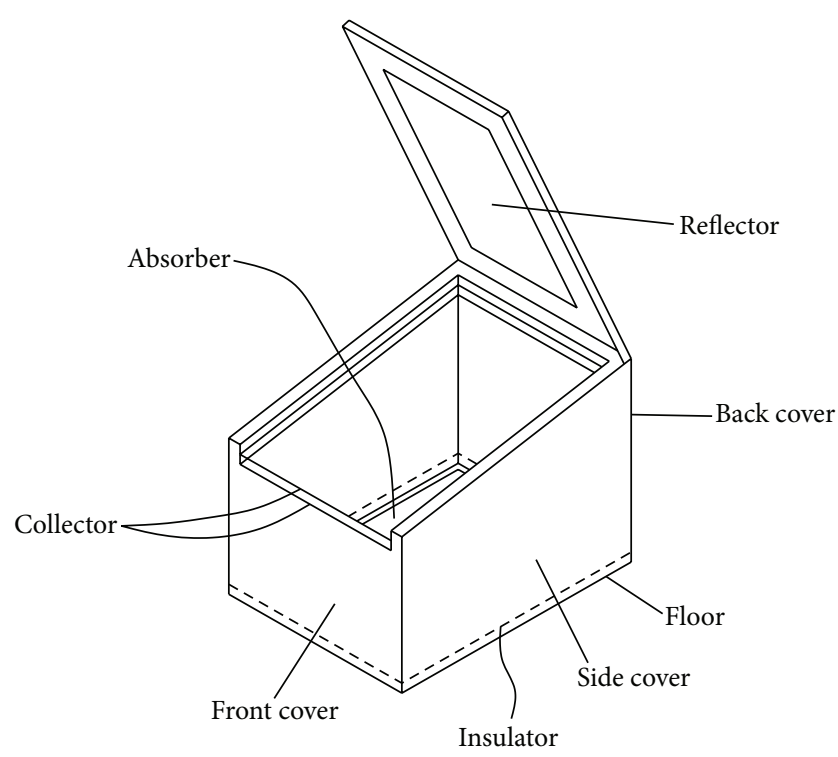

FIGURE 1: Box-type solar oven.

(ii) tray-inner cooker box, aluminium sheet of $1 \mathrm{~mm},(600$ $\times 600 \times 300 \mathrm{~mm}, k=80 \mathrm{~W} / \mathrm{m}^{\circ} \mathrm{C}$, emissivity $=0.9 ;$

(iii) glazing (double), ordinary glass sheets of $4 \mathrm{~mm}$, $600 \mathrm{~mm} \times 600 \mathrm{~mm}$ spacing between sheets $40 \mathrm{~mm}$;

(iv) insulation-fibre glass, $50 \mathrm{~mm}, k=0.052 \mathrm{~W} / \mathrm{m}^{\circ} \mathrm{C}$;

(v) reflectors (mirrors), silvered glass mirror of $2 \mathrm{~mm}$, $700 \times 700 \mathrm{~mm}$

(vi) cooking pot, aluminium cylindrical diameter = $300 \mathrm{~mm}$, height $=300 \mathrm{~mm}$, with dull black paint;

(vii) aperture area of $0.6 \mathrm{~m} \times 0.6 \mathrm{~m}$.

\section{Design Equations for Operation of Solar Cookers}

4.1. Concentration Ratio. The principle of solar cooking is that rays of sun are converted to heat and conducted into the cooking pot. The ability of a solar cooker to collect sunlight is directly related to the projected area of the collector perpendicular to the incident radiation. In this regard, the geometric concentration ratio is defined as

$$
\mathrm{CR}=\frac{A_{t}}{A_{\mathrm{rc}}}
$$

where $A_{t}$ is the total collector area and $A_{\mathrm{rc}}$ is the area of the receiver/absorber surface.

4.2. Overall Instantaneous Insolation. The overall instantaneous insolation, $I_{T}$, incident on a unit horizontal surface area of the solar cooker with a single reflector is given as

$$
I_{T}=I_{b}+I_{d}+I_{r}
$$

where $I_{b}$ and $I_{d}$ are the beam and diffuse components of insolation impinging directly on the cooker glazing and $I_{r}$ is the beam insolation reflected on the plane reflector surface to the cooker glazing. These insolation components are further defined as follows according to Taha and Eldighidy, [8]:

$$
\begin{gathered}
I_{b}=A \exp \left(\frac{-B}{\sin \alpha}\right) \cos \theta_{g}, \\
I_{d}=A C \exp \left(\frac{-B}{\sin \alpha}\right) f_{\mathrm{gs}}, \\
I_{r}=\rho_{r} I_{\mathrm{br}} f_{\mathrm{rg}} \cos \theta_{\mathrm{rg}}, \\
I_{\mathrm{br}}=A \exp \left(\frac{-B}{\sin \alpha}\right) \cos \theta_{r}, \\
f_{\mathrm{rg}}=\frac{(1+\cos \beta)}{2},
\end{gathered}
$$

where $I_{\mathrm{br}}$ is the beam insolation incident on the plane reflector, $A$ (in $\mathrm{Wm}^{-2}$ ), $B$ and $C$ are constants determined for average days of the months, $\alpha$ is the solar altitude angle ( $\alpha=$ $90-\theta z), \theta_{g}$ and $\theta_{r}$ are the incident angles of beam insolation on the cooker glazing and plane reflector, respectively, $\theta_{\mathrm{rg}}$ is the incident angle of the reflected beam insolation on the cooker surface, $f_{\mathrm{gs}}$ is the view factor of the glazing and sky for a horizontal cooker, $(\beta=0$, the surface is completely covered by the sky, $\left.f_{\mathrm{gs}}=1\right), f_{\mathrm{rg}}$ is the reflector-glazing exchange factor, defined as the area of the glazing that is exposed to the reflected radiation (if the reflector and cooker are so adjusted that the cooker surface is completely exposed to the reflected radiation, then $\left.f_{\mathrm{rg}}=1\right), \rho_{r}$ is the reflectivity of the reflector mirror (given as 0.89). For a horizontal cooker surface, the tilt angle, $\beta=0$, and incident angle of beam insolation on the glazing $=$ zenith angle. The rate of energy absorbed by the cooker can thus be given as

$$
q=\left[(\tau \alpha)_{b} I_{b}+(\tau \alpha)_{d} I_{d}+(\tau \alpha)_{r} I_{r}\right](1-D)(1-S)\left(1-S_{\mathrm{rg}}\right),
$$

where $(\tau \alpha)_{b}$ are the transmittance-absorptance products for the beam radiation (dimensionless), $(\tau \alpha)_{d}$ are the transmittance-absorptance products for the diffuse radiation (dimensionless), and $(\tau \alpha)_{r}$ are the transmittance-absorptance products for the reflected radiation (dimensionless).

According to Duffie and Beckman, [9] the above dimension can be calculated for the respective angles of incident for practical purposes, a good approximation is that $(\tau \alpha)=$ $1.01 \tau \alpha$, and according to Grassie and Sheridan [10], $D$ is the effect due to dust (for regularly cleaned glazing, $D=0.01, S$ is a shading factor due to the cooker walls which is assumed to vary sinusoidally with a period equal to day length and with a maximum of 0.1 at sunrise and sunset and zero at solar noon, $S$ can be neglected since the cooker is regularly adjusted and cooker walls also act as absorbers); $S_{\text {rg }}$ is shading effect due to the reflector on the absorber calculated, if the reflector and cooker are so adjusted that the cooker surface is completely exposed to the reflected radiation, and $S_{\mathrm{rg}}$ can be neglected.

4.3. Collector Tilt. The flat plate collector requires no tracking of the sun if it is permanently fixed in position. Usually, the collector should be oriented directly toward the equator, 
facing south in northern hemisphere and facing north in the southern hemisphere. Generally, for all year, applications like domestic hot water heating and year round air conditioning of buildings the optimum tilt angle of the collector is equal to the latitude. For space heating in winter only the tilt angle should be approximately $10^{\circ}$ to $15^{\circ}$ more than the latitude [11]. It is note worthy, however, that optimum surface tilt and surface azimuth are not really critical; deviations as much as $10^{\circ}$ from the optimum values result in only small reduction in total annual energy availability [12]. The collector for this particular design is tilted $10^{\circ}$ considering the geographical location of Minna (latitude $9.58^{\circ} \mathrm{N}$ and longitude $6.33^{\circ} \mathrm{E}$ ).

\section{Solar Cooker Thermal Performance}

5.1. First Figure of Merit $\left(F_{1}\right)$. The first figure of merit $\left(F_{1}\right)$ is defined as the ratio of optical efficiency, $\left(\eta_{o}\right)$, and the overall heat loss coefficient, $\left(U_{L}\right)$. A quasi-steady state (stagnation test condition) is achieved when the stagnation temperature is attained. High optical efficiency and low heat loss are desirable for efficient cooker performance. Thus the ratio $\eta_{o} / U_{L}$ which is a unique cooker parameter can serve as a performance criterion. Higher values of $F_{1}$ would indicate better cooker performance:

$$
F_{1}=\frac{\eta_{o}}{U_{L}}=\frac{\left(T_{p}-T_{a}\right)}{I_{s}}
$$

where $F_{1}$ is first figure of merit $\left(\mathrm{Km}^{2} \mathrm{w}^{-1}\right), \eta_{o}$ is optical efficiency (\%), $U_{L}$ is overall heat loss factor $\left(\mathrm{Wk}^{-1} \mathrm{~m}^{-2}\right), T_{p}$ is absorber plate temperature $\left({ }^{\circ} \mathrm{C}\right), T_{a}$ is ambient temperature $\left({ }^{\circ} \mathrm{C}\right)$, and $I_{s}$ is insolation on a horizontal surface $\left(\mathrm{Wm}^{-2}\right)$.

5.2. Second Figure of Merit $\left(F_{2}\right)$. The second figure of merit, $F_{2}$, of box type solar cooker is evaluated under full-load condition and can be defined as the product of the heat exchanger efficiency factor $\left(F^{\prime}\right)$ and optical efficiency $\left(\eta_{0}=\right.$ $\alpha \tau)$ [13]. It can be expressed as

$$
F_{2}=F^{\prime} \eta_{o}=\frac{F_{1}(M C)_{w}}{A\left(t_{2}-t_{1}\right)} \operatorname{In}\left[\frac{1-\left(1 / F_{1}\right)\left(\left(T_{w 1}-T_{a}\right) / I_{s}\right)}{1-\left(1 / F_{1}\right)\left(\left(T_{w 2}-T_{a}\right) / I_{s}\right)}\right],
$$

where $F_{1}$ is first figure of merit $\left(\mathrm{Km}^{2} \mathrm{w}^{-1}\right), M$ is mass of water (kg), $C$ is specific heat capacity of water $\left(\mathrm{J} / \mathrm{Kg}^{\circ} \mathrm{C}\right), A$ is aperture area of the solar cooker $\left(\mathrm{m}^{2}\right), t_{1}$ is initial time $(\mathrm{s}), t_{2}$ is final time (s), $T_{w 1}$ is initial water temperature $\left({ }^{\circ} \mathrm{C}\right), T_{w 2}$ is final water temperature $\left({ }^{\circ} \mathrm{C}\right), I_{s}$ is average insolation $\left(\mathrm{W} / \mathrm{m}^{2}\right)$, and $T_{a}$ is average ambient temperature $\left({ }^{\circ} \mathrm{C}\right)$.

\subsection{Cooking Power Estimation}

5.3.1. Interval Cooking Power. The average cooking power, $P$, is defined as the rate of useful energy available during heating period. It may be determined as a product of the change in water temperature for each interval and mass and specific heat capacity of the water contained in the cooking utensil. Dividing the product by the time (10-minute intervals according to American Society of Agricultural Engineers) contained in a periodic interval yields the cooking power in Watts:

$$
P=\frac{(M C)_{w}\left(T_{2}-T_{1}\right)}{600}
$$

where $P$ is interval cooking power (W), $T_{1}$ is initial water temperature $\left({ }^{\circ} \mathrm{C}\right), T_{2}$ is final water temperature $\left({ }^{\circ} \mathrm{C}\right), M$ is mass of water $(\mathrm{kg})$, and $C$ is specific heat capacity $(4186 \mathrm{~J} / \mathrm{kg}$ $\mathrm{K})$.

5.3.2. Standardized Cooking Power $\left(P_{s}\right)$. To determine the standardizing cooking power, $P_{s}$, from the cooking power, $P$, each interval is corrected to a standard insolation of $700 \mathrm{~W} / \mathrm{m}^{2}$ :

$$
P_{s}=\frac{P \times 700}{I_{s}}
$$

where $P_{s}$ is standardized cooking power (W), $P$ is interval cooking power $(\mathrm{W})$, and $I_{s}$ is interval average solar insolation $\left(\mathrm{W} / \mathrm{m}^{2}\right)$.

5.3.3. Temperature Difference. This is the difference between ambient temperature for each interval and the average cooking vessel contents temperature for each corresponding interval:

$$
T_{d}=T_{w}-T_{a},
$$

where $T_{d}$ is temperature difference $\left({ }^{\circ} \mathrm{C}\right), T_{w}$ is water temperature $\left({ }^{\circ} \mathrm{C}\right)$, and $T_{a}$ is ambient temperature $\left({ }^{\circ} \mathrm{C}\right)$.

\section{Apparatus and Materials for Testing}

Digital pyranometer, digital anemometer, K-type (i.e., copper and constantine) thermocouples, aluminium cooking vessels, and electronic mass balance.

\section{Testing}

A procedure for testing the solar cookers was developed based on existing international testing standards. They include three major testing standards for solar cookers that are commonly employed in different parts of the world. These are the American Society of Agricultural Engineers Standard [14], Bureau of Indian Standards Testing Method, and European Committee on Solar Cooking Research Testing Standard and others [15]. Based on the existing international testing standards three tests were performed on the solar oven, these are

(i) the stagnation temperature Test;

(ii) thermal load test, heat up condition test;

(iii) cooking power estimation. 
TABLE 1: Stagnation temperature test $\left(F_{1}\right)(03 / 03 / 2013)$.

\begin{tabular}{lcccc}
\hline Time (hrs) & $\begin{array}{c}\text { Ambient temp. } \\
T_{a}\left({ }^{\circ} \mathrm{C}\right)\end{array}$ & $\begin{array}{c}\text { Plate temp. } \\
T_{p}\left({ }^{\circ} \mathrm{C}\right)\end{array}$ & $\begin{array}{c}\text { Insolation } \\
I_{s}\left(\mathrm{~W} / \mathrm{m}^{2}\right)\end{array}$ & $\begin{array}{c}\text { Wind } \\
\text { speed } \\
(\mathrm{m} / \mathrm{s})\end{array}$ \\
\hline 10.00 & 29 & 68 & 623.81 & 2.5 \\
10.30 & 29 & 79 & 652.12 & 2.5 \\
11.00 & 31 & 81 & 698.34 & 2.4 \\
11.30 & 32 & 90 & 701.08 & 2.0 \\
12.00 & 33 & 95 & 729.11 & 2.2 \\
12.30 & 35 & 103 & 737.03 & 2.0 \\
13.00 & 35 & 119 & 740.12 & 2.0 \\
13.30 & 34 & 112 & 728.45 & 2.1 \\
14.00 & 32 & 110 & 725.56 & 2.0 \\
\hline
\end{tabular}

7.1. The Stagnation Temperature Test. The stagnation temperature test was conducted for the evaluation of first figure of merit $\left(F_{1}\right)$ of solar cooker. The quasi-steady state, the final steady cooker tray temperature, is achieved when the stagnation temperature is attained. The procedure for determining stagnation temperature is stated as follows.

(i) The box-type solar cooker was placed in the open sun without load with the reflector being covered with black cloth.

(ii) Type " $k$ " calibrated thermocouples were connected to the solar cooker to measure both the cooker tray and ambient temperatures simultaneously at a given interval till the stagnation condition was reached. These measurements were recorded.

(iii) Intensity of total solar radiation on horizontal surface and wind speed at the level of aperture of the box cooker were monitored, measured, and recorded at regular interval using digital radiation pyranometer and digital anemometer, respectively.

(iv) The data of the stagnation test is given in Table 1 below.

7.2. Thermal Load Test, Heat up Condition Test. The thermal load test was conducted to determine the second figure of merit $F_{2}$ and it was evaluated under full-load condition. The solar box cooker was loaded with $2 \mathrm{~kg}$ of water at $48^{\circ} \mathrm{C}$ in an aluminium cooking vessel painted black; the water temperature was initially above the ambient temperature. Solar radiation, ambient air temperature, water temperature, and time were recorded at a regular interval till the water temperature exceeded $95^{\circ} \mathrm{C}$. The initial and final water temperatures were chosen between $65^{\circ} \mathrm{C}$ and $95^{\circ} \mathrm{C}$, respectively. In summary the following measurements were made during the test:

(i) the water temperature at a regular time interval until the water temperature exceed $95^{\circ} \mathrm{C}$;

(ii) time duration between initial and final water temperatures was recorded;
TABLE 2: Thermal load test, heat up condition test $\left(F_{2}\right)(06 /$ 03/2013).

\begin{tabular}{lcccc}
\hline Time (hrs) & $\begin{array}{c}\text { Ambient temp. } \\
T_{a}\left({ }^{\circ} \mathrm{C}\right)\end{array}$ & $\begin{array}{c}\text { Water temp. } \\
T_{w}\left({ }^{\circ} \mathrm{C}\right)\end{array}$ & $\begin{array}{c}\text { Insolation } \\
I_{s}\left(\mathrm{~W} / \mathrm{m}^{2}\right)\end{array}$ & $\begin{array}{c}\text { Wind } \\
\text { speed } \\
(\mathrm{m} / \mathrm{s})\end{array}$ \\
\hline 10.00 & 28 & 48 & 604.61 & 2.5 \\
10.30 & 29 & 56 & 642.62 & 2.5 \\
11.00 & 31 & 66 & 668.24 & 2.5 \\
11.30 & 32 & 73 & 691.48 & 2.3 \\
12.00 & 33 & 84 & 719.31 & 2.2 \\
12.30 & 35 & 87 & 727.23 & 2.2 \\
13.00 & 35 & 93 & 737.52 & 2.0 \\
13.30 & 34 & 96 & 725.45 & 2.1 \\
14.00 & 32 & 89 & 725.16 & 2.0 \\
\hline
\end{tabular}

TABLE 3: Thermal load test, heat up condition test $\left(F_{2}\right)(07 / 03 / 2013)$.

\begin{tabular}{lcccc}
\hline Time (hrs) & $\begin{array}{c}\text { Ambient temp. } \\
T_{a}\left({ }^{\circ} \mathrm{C}\right)\end{array}$ & $\begin{array}{c}\text { Water temp. } \\
T_{w}\left({ }^{\circ} \mathrm{C}\right)\end{array}$ & $\begin{array}{c}\text { Insolation } \\
I_{s}\left(\mathrm{~W} / \mathrm{m}^{2}\right)\end{array}$ & $\begin{array}{c}\text { Wind } \\
\text { speed } \\
(\mathrm{m} / \mathrm{s})\end{array}$ \\
\hline 10.00 & 29 & 48 & 614.63 & 2.6 \\
10.30 & 30 & 57 & 644.72 & 2.5 \\
11.00 & 32 & 67 & 666.34 & 2.5 \\
11.30 & 33 & 78 & 693.28 & 2.2 \\
12.00 & 35 & 85 & 721.11 & 2.2 \\
12.30 & 35 & 93 & 737.23 & 2.2 \\
13.00 & 35 & 95 & 740.52 & 2.0 \\
13.30 & 34 & 92 & 735.45 & 2.1 \\
14.00 & 33 & 89 & 725.16 & 2.0 \\
\hline
\end{tabular}

(iii) the average ambient temperature and average solar radiation intensity between initial and final time were calculated. The data of the full load test is given in Tables 2 and 3.

In order to minimize error in the results obtained the following precautionary steps were taken.

(i) The test was conducted in clear weather, and it was ensured that the solar radiation during the test exceeded $600 \mathrm{~W} / \mathrm{m}^{2}$.

(ii) Water and ambient temperatures were measured with $k$-type thermocouples. Each thermocouple junction was immersed in the water in the cooking vessel and secured $10 \mathrm{~mm}$ above the bottom, at centre. Thermocouples leads were made to pass through the cooking vessel lid inside a thermally nonconductive sleeve to protect the thermocouple wires from bending and temperature extremes. The sleeve was secured with $100 \%$ silicone caulk to reduce water vapour loss. 


\subsection{Cooking Power Estimation}

\subsubsection{Steps for the Determination of Cooking Power}

(i) The solar box cooker was loaded with $2 \mathrm{~kg}$ of water in an aluminium cooking vessel painted black. The average water temperature in the cooking vessel was recorded at intervals of ten minutes. Solar insolation, ambient temperature, and wind speed were also recorded at least as frequently.

(ii) The change in water temperature for each ten-minute interval was multiplied by the mass and specific heat capacity of the water contained in the cooking vessel. This product was divided by the 600 seconds contained in a ten-minute interval to determine cooking power of the cooker as shown in (7).

(iii) In order to determine the standardizing cooking power, cooking power for each interval was corrected to a standard insolation of $700 \mathrm{~W} / \mathrm{m}^{2}$ by multiplying the interval observed cooking power by $700 \mathrm{~W} /$ $\mathrm{m}^{2}$ and dividing by the interval average insolation recorded during the corresponding interval as shown (8).

(iv) Cooking power, $P$, and standardized cooking power, $P_{s}$, were calculated by (7) and (8). The Standardized cooking power, $P_{s}$, was plotted against the temperature difference, $T_{d}$, for each time interval. Temperature difference, $T_{d}$, was calculated by (9). A linear regression of the plotted points was used to find the relationship between cooking power and temperature difference in terms of intercept, $\mathrm{W}$, and slope, $\mathrm{W} /{ }^{\circ} \mathrm{C}$. The thermal performance of the box type solar cooker was evaluated according to the international standards of American Society of Agricultural Engineers (ASAE), and in this standard it is recommended to use linear fit. The coefficient of determination, $R^{2}$, or proportion of variation in cooking power that can be attributed to the relationship found by regression should be better than 0.75 according to Funk and Larson. The value for standardized cooking power, $P_{s}$, was calculated for a temperature difference, $T_{d}$, of $50^{\circ} \mathrm{C}$ using the previous determined relationship.

\section{Results}

See Tables 1, 2, 3, and 4 and Figures 2, 3, 4, and 5.

\section{Discussion of Results}

The results of this research work will be discussed under the following:

(i) stagnation temperature test of solar cooker for first figure of merit $\left(F_{1}\right)$;

(ii) water heat up test of solar cooker for second figure of merit $\left(F_{2}\right)$;

(iii) standard cooking power estimation.



FIGURE 2: Stagnation temperature test of solar cooker for first figure of merit $\left(F_{1}\right)(03 / 03 / 2013)$.

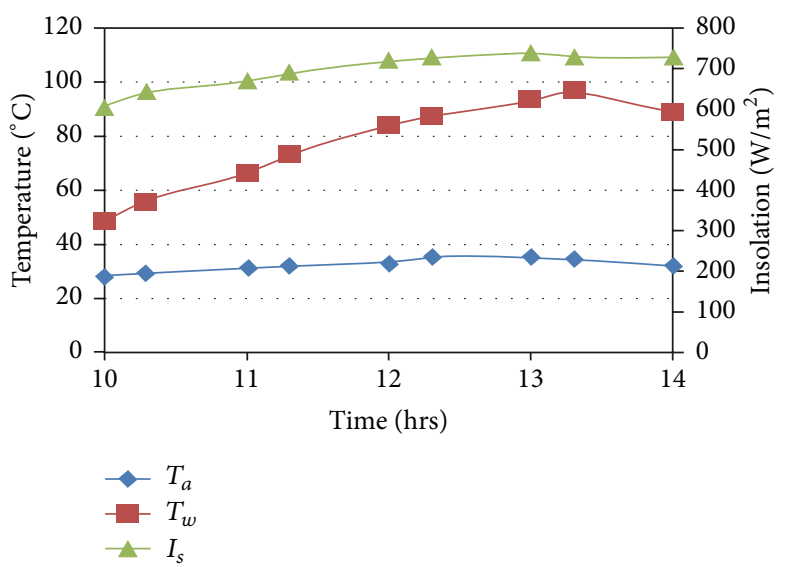

FIGURE 3: Water heat up test of solar cooker for second figure of merit $\left(F_{2}\right)(06 / 03 / 2013)$.

The thermal evaluation experiment to determine the stagnation temperature of the box-type solar cooker was carried out on 3rd March, 2013, having a suitable clear sky. The developed solar cooker was tested at Minna (latitude $9.58^{\circ} \mathrm{N}$ and longitude $6.33^{\circ} \mathrm{E}$ ). The stagnation temperature test that is, no load test was started at 10.00 am local time till the maximum plate temperature $\left(119^{\circ} \mathrm{C}\right)$, which occurred at $13.00 \mathrm{pm}$, was achieved. The following measurements were taken: solar radiation power, ambient air temperature, and base plate temperature at a regular interval. This test was performed in order to determine the first figure of merit of the cooker and compare it with the standard. Results are shown in Table 1. From Table 1 the following values were obtained in order to compute $F_{1}: T_{a}=35^{\circ} \mathrm{C}, T_{p}=119^{\circ} \mathrm{C}, I_{s}=$ $740.12 \mathrm{~W} / \mathrm{m}^{2}$. Equation (5) was used to compute $F_{1}$. However, the obtained value of $F_{1}$ is $\left(0.11 \mathrm{Km}^{2} \mathrm{w}^{-1}\right)$ where the allowed standard $F_{1}$ test states that if the value of $F_{1}$ is greater than 0.12 , the cooker is marked as A-Grade and if $F_{1}$ is less than 0.12 the cooker is marked as a B-Grade solar cooker [13]. The constructed cooker is marked as a B-Grade solar cooker, and 
TABLE 4: Cooking power estimation (09/03/2013).

\begin{tabular}{|c|c|c|c|c|c|c|c|c|}
\hline Time interval (Min.) & $T_{1}\left({ }^{\circ} \mathrm{C}\right)$ & $T_{2}\left({ }^{\circ} \mathrm{C}\right)$ & $P(\mathrm{~W})$ & $I_{s}\left(\mathrm{~W} / \mathrm{m}^{2}\right)$ & $P_{s}(\mathrm{~W})$ & $T_{a}\left({ }^{\circ} \mathrm{C}\right)$ & $T_{w}\left({ }^{\circ} \mathrm{C}\right)$ & $T_{d}\left({ }^{\circ} \mathrm{C}\right)$ \\
\hline 10.10 & 30.0 & 33.0 & 41.86 & 600.00 & 48.84 & 30.0 & 33.0 & 3.0 \\
\hline 10.20 & 33.0 & 36.0 & 41.86 & 625.57 & 46.84 & 30.0 & 36.0 & 6.0 \\
\hline 10.30 & 36.0 & 38.8 & 39.06 & 630.41 & 43.37 & 30.0 & 38.8 & 8.8 \\
\hline 10.40 & 38.8 & 41.8 & 41.86 & 637.14 & 45.99 & 30.0 & 41.8 & 11.8 \\
\hline 10.50 & 41.8 & 43.8 & 41.86 & 643.15 & 45.56 & 30.0 & 43.8 & 13.8 \\
\hline 11.00 & 43.8 & 46.8 & 41.86 & 649.14 & 45.14 & 31.0 & 46.8 & 15.8 \\
\hline 11.10 & 46.8 & 49.7 & 40.46 & 651.00 & 43.51 & 31.0 & 49.7 & 18.7 \\
\hline 11.20 & 49.7 & 52.7 & 41.86 & 667.47 & 43.90 & 32.0 & 52.7 & 20.7 \\
\hline 11.30 & 52.7 & 55.7 & 41.86 & 698.00 & 41.98 & 32.0 & 55.7 & 23.7 \\
\hline 11.40 & 55.7 & 58.7 & 41.86 & 724.40 & 40.45 & 32.0 & 58.7 & 26.7 \\
\hline 11.50 & 58.7 & 61.6 & 40.46 & 739.00 & 38.32 & 32.0 & 61.6 & 29.6 \\
\hline 12.00 & 61.6 & 64.6 & 41.86 & 746.75 & 39.23 & 33.0 & 64.6 & 31.6 \\
\hline 12.10 & 64.6 & 67.5 & 40.46 & 750.39 & 37.74 & 33.0 & 67.5 & 34.5 \\
\hline 12.20 & 67.5 & 70.2 & 37.67 & 756.17 & 34.87 & 33.0 & 70.2 & 37.2 \\
\hline 12.30 & 70.2 & 72.8 & 36.27 & 764.02 & 33.23 & 33.0 & 72.8 & 39.8 \\
\hline 12.40 & 72.8 & 75.2 & 33.48 & 770.32 & 30.42 & 34.0 & 75.2 & 41.2 \\
\hline 12.50 & 75.2 & 77.4 & 30.69 & 772.23 & 27.82 & 34.0 & 77.4 & 43.4 \\
\hline 13.00 & 77.4 & 79.5 & 29.20 & 773.21 & 26.44 & 35.0 & 79.5 & 44.5 \\
\hline 13.10 & 79.5 & 81.5 & 27.90 & 776.85 & 25.14 & 35.0 & 81.5 & 46.5 \\
\hline 13.20 & 81.5 & 83.4 & 26.51 & 789.09 & 23.52 & 35.0 & 83.4 & 48.4 \\
\hline 13.30 & 83.4 & 85.1 & 23.72 & 794.01 & 20.91 & 34.0 & 85.1 & 51.1 \\
\hline 13.40 & 85.1 & 86.7 & 22.32 & 796.44 & 19.62 & 35.0 & 86.7 & 51.7 \\
\hline 13.50 & 86.7 & 88.2 & 20.93 & 797.16 & 18.38 & 35.0 & 88.2 & 53.2 \\
\hline 14.00 & 88.2 & 89.7 & 20.93 & 799.44 & 18.33 & 35.0 & 89.7 & 54.7 \\
\hline
\end{tabular}

Note: Test started $10.00 \mathrm{am}$, Average wind speed $=2.45 \mathrm{~m} / \mathrm{s}$.



FIGURE 4: Water heat up test of solar cooker for second figure of merit $\left(F_{2}\right)(07 / 03 / 2013)$.

Figure 1 shows the relationship between measured values. The low value of first figure of merit may be an indication that there were higher convection and radiation losses from the side walls made of compressed sawdust and maybe the side insulator is not thick enough.

Water heat up test experiment of the solar cooker was conducted in order to determine the second figure of merit

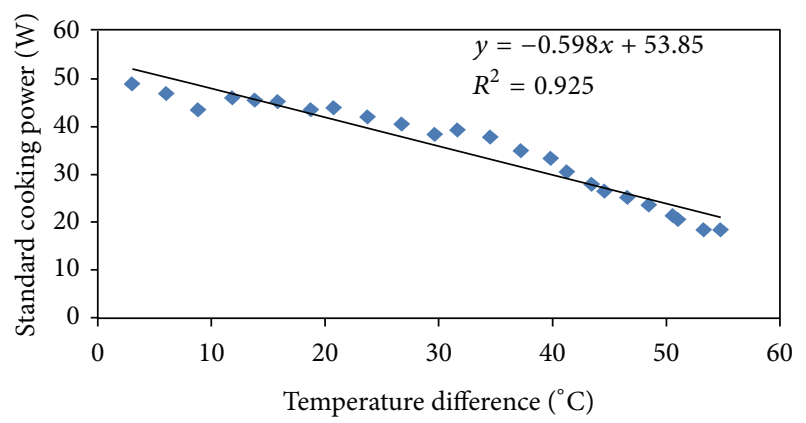

FIGURE 5: Standard cooking power plotted over temperature difference (09/03/2013).

$\left(F_{2}\right)$. The test was carried out for two consecutive test days (March 6, 2013 and March 7, 2013) in a clear sky conditions following the International Standard Procedure. For the fullload test water temperatures for $T_{w 1}=65^{\circ} \mathrm{C}$ and $T_{w 2}=95^{\circ} \mathrm{C}$ were chosen. The following values were recorded at a regular interval during the experiment: ambient temperature, water temperature, insolation, wind speed, and time for the water temperature to increase from $T_{w 1}$ to $T_{w 2}$ as shown in Tables 2 and 3. For the computation of $F_{2}$ the following values are obtained from Tables 2 and 3. 
Day 1. $F_{1}=0.1135 \mathrm{Km}^{2} \mathrm{w}^{-1}$ (computed), $M=2.0 \mathrm{~kg}, c=$ $4186 \mathrm{~J} / \mathrm{kg}^{\circ} \mathrm{C}, t_{2}-t_{1}=136 \mathrm{~min}$. (8160 secs), $A=0.36 \mathrm{~m}^{2} \mathrm{~T}_{w 1}=$ $65^{\circ} \mathrm{C}, T_{w 2}=95^{\circ} \mathrm{C}, I_{\text {ave }}=708.76 \mathrm{~W} / \mathrm{m}^{2}, T_{\text {ave }}=33.2^{\circ} \mathrm{C}$, and $F_{2}=0.3102$.

Day 2. $F_{1}=0.1135 \mathrm{Km}^{2} \mathrm{w}^{-1}$ (computed), $M=2.0 \mathrm{~kg}, c=$ $4186 \mathrm{~J} / \mathrm{kg}^{\circ} \mathrm{C}, t_{2}-t_{1}=128 \mathrm{~min}$. (7680 secs), $A=0.36 \mathrm{~m}^{2}$ $T_{w 1}=65^{\circ} \mathrm{C}, T_{w 2}=95^{\circ} \mathrm{C}, I_{\text {ave }}=711.70 \mathrm{~W} / \mathrm{m}^{2}, T_{\text {ave }}=34.0^{\circ} \mathrm{C}$, and $F_{2}=0.3172$.

Using (6) second figure of merit was computed for the two consecutive days to be 0.31 which is less than recommended standard value of greater than 0.40 [13]. Figures 2 and 3 show relationship between ambient temperature, water temperature, and the solar insolation.

Cooking power experiment was conducted based on international standard procedure on March 9, 2013. Experiment was conducted for the load of $2.0 \mathrm{~kg}$ of water. Solar cooker was exposed to the sun at 10.00 am (local time) to $14.00 \mathrm{pm}$ (local time), and the following values were recorded at 10-minute interval: initial temperature of water, final temperature of water, ambient temperature, average wind speed, and solar insolation as shown in Table 4. From the data recorded (7), (8), and (9) were used, respectively, to calculate $P, P_{s}$, and $T_{d}$ for each interval. Standard cooking power $\left(P_{s}\right)$ is plotted against the difference between water temperature and ambient temperature $\left(T_{d}\right)$ as shown in Figure 4 . A linear regression was used to examine the relationship between standard cooking power and temperature difference. Figure 4 shows that the cooking regression equation is $P_{s}=53.85-$ $0.598 T_{d}$. The value of the coefficient of determination $\left(R^{2}\right)$ of the equation is $0.925>0.75$ (recommended standard value). The cooking power at $50^{\circ} \mathrm{C}$ temperature difference was calculated using the regression equation $P_{50}=23.95 \mathrm{~W}$. Figure 4 shows that as temperature difference increases, the standard cooking power decreases.

\section{Conclusion}

The experimental results obtained from the thermal performance tests carried out show that the box-type solar cooker employing a nontracking solar concentrator could provide improved heat collection and hence efficient cooking. The cooker offers advantages of faster cooking and hence reducing the cooking time considerably. It can therefore be used in Minna for fast and effective cooking of various types of foods.

\section{References}

[1] L. R. Fagbenle, "Estimation of total solar radiation in Nigeria using meteorological data," Journal of Renewable Energy, vol. 1, no. 1, pp. 1-10, 1990.

[2] B. Garba, A. J. Atiku, and A. K. Madukwe, "Solar cookers," Nigerian Journal of Renewable Energy, vol. 4, no. 2, pp. 1-11, 2000.

[3] United Nations Industrial Development Organization [UNIDO], Technology for Solar Utilization, vol. 5 of Development and Transfer of Technology series, New York, NY, USA, 1978.
[4] J. F. Kreider and F. Kreth, Solar heating and cooking (active and passive design), Hemisphere Publishing Corporation, Washington, DC, USA, 2003.

[5] V. Ceserani and R. Kinton, Practical Cookery, Hooder and Stoughton Educational, London, UK, 1993.

[6] M. M. Hoda, Technology of Cooking: Solar Cookers, Appropriate Technology Development, New Delhi, India, 2001.

[7] S. Ajisegiri, Solar Energy Application in Agriculture and Food Presentation Minna, Jameson, 2001.

[8] I. S. Taha and S. M. Eldighidy, "Effect of off-south orientation on optimum conditions for maximum solar energy absorbed by flat plate collector augmented by plane reflector," Solar Energy, vol. 25, no. 4, pp. 373-379, 1980.

[9] J. A. Duffie and W. A. Beckman, Solar Engineering of Thermal Processes, Wiley Interscience, New York, NY, USA, 1980.

[10] S. L. Grassie and N. R. Sheridan, "The use of planar reflectors for increasing the energy yield of flat-plate collectors," Solar Energy, vol. 19, no. 6, pp. 663-668, 1977.

[11] J. A. Duffie and W. A. Beckman, Solar Energy Thermal Process, John Wiley and Sons, New York, NY, USA, 1997.

[12] T. C. Thwasi, K. Das, and D. P. Rao, "Solar box-cooker: part Imodeling," Solar Energy Journal, vol. 52, no. 3, pp. 267-272, 1998.

[13] S. C. Mullick, T. C. Kandpal, and S. Kumar, "Testing of box-type solar cooker: second figure of merit F2 and its variation with load and number of pots," Solar Energy, vol. 57, no. 5, pp. 409413, 1996.

[14] ASAE, 2003, ASAE S580: Testing and Reporting of Solar Cooker Performance.

[15] P. A. Funk and D. L. Larson, "Parametric model of solar cooker performance," Solar Energy, vol. 62, no. 1, pp. 63-68, 1998. 


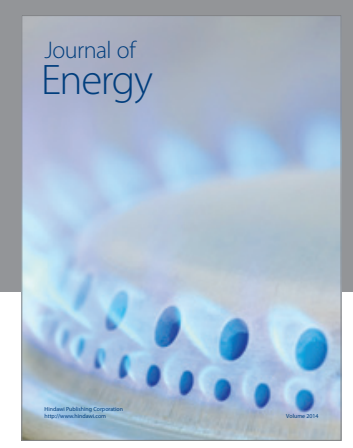

Journal of

Industrial Engineering
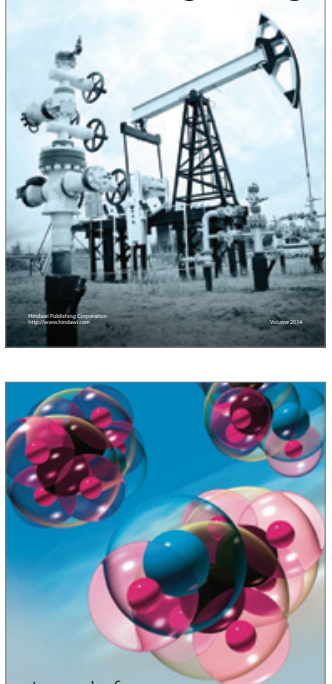

Fuels
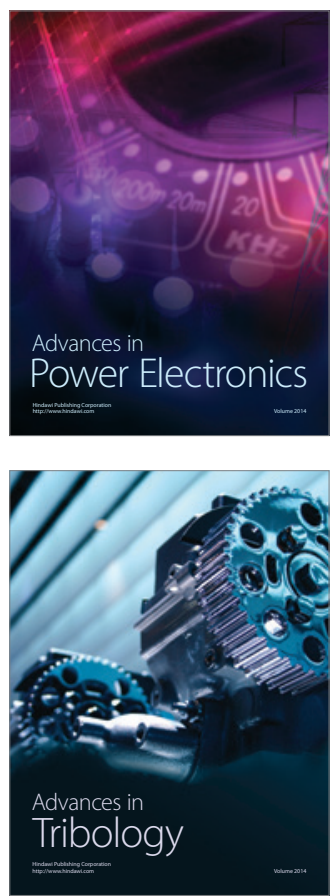

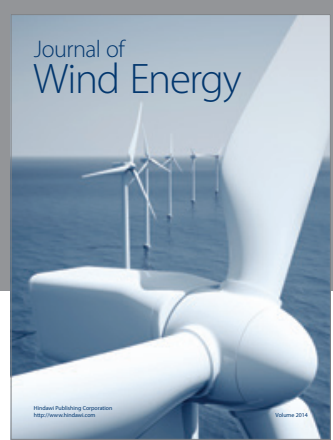

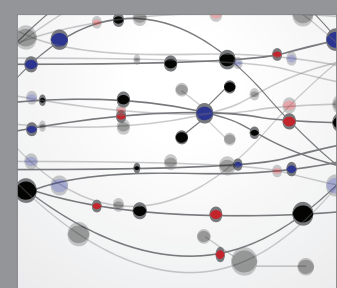

The Scientific World Journal

Submit your manuscripts at http://www.hindawi.com

Journal of

Structures


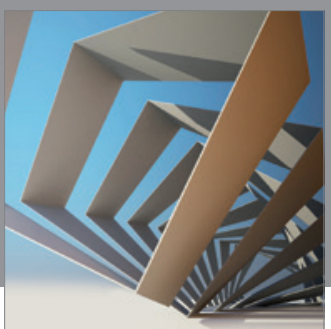

Rotating

Machinery
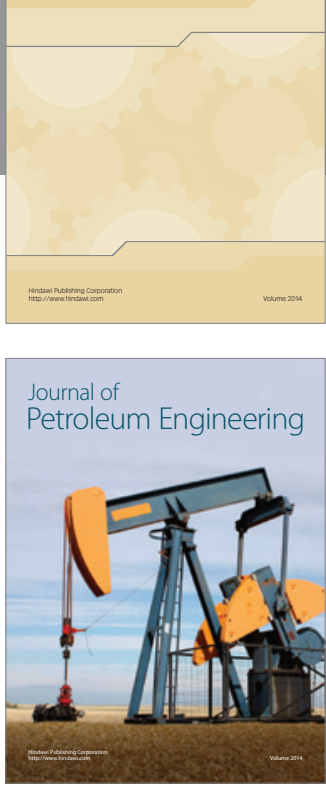

Journal of

Solar Energy
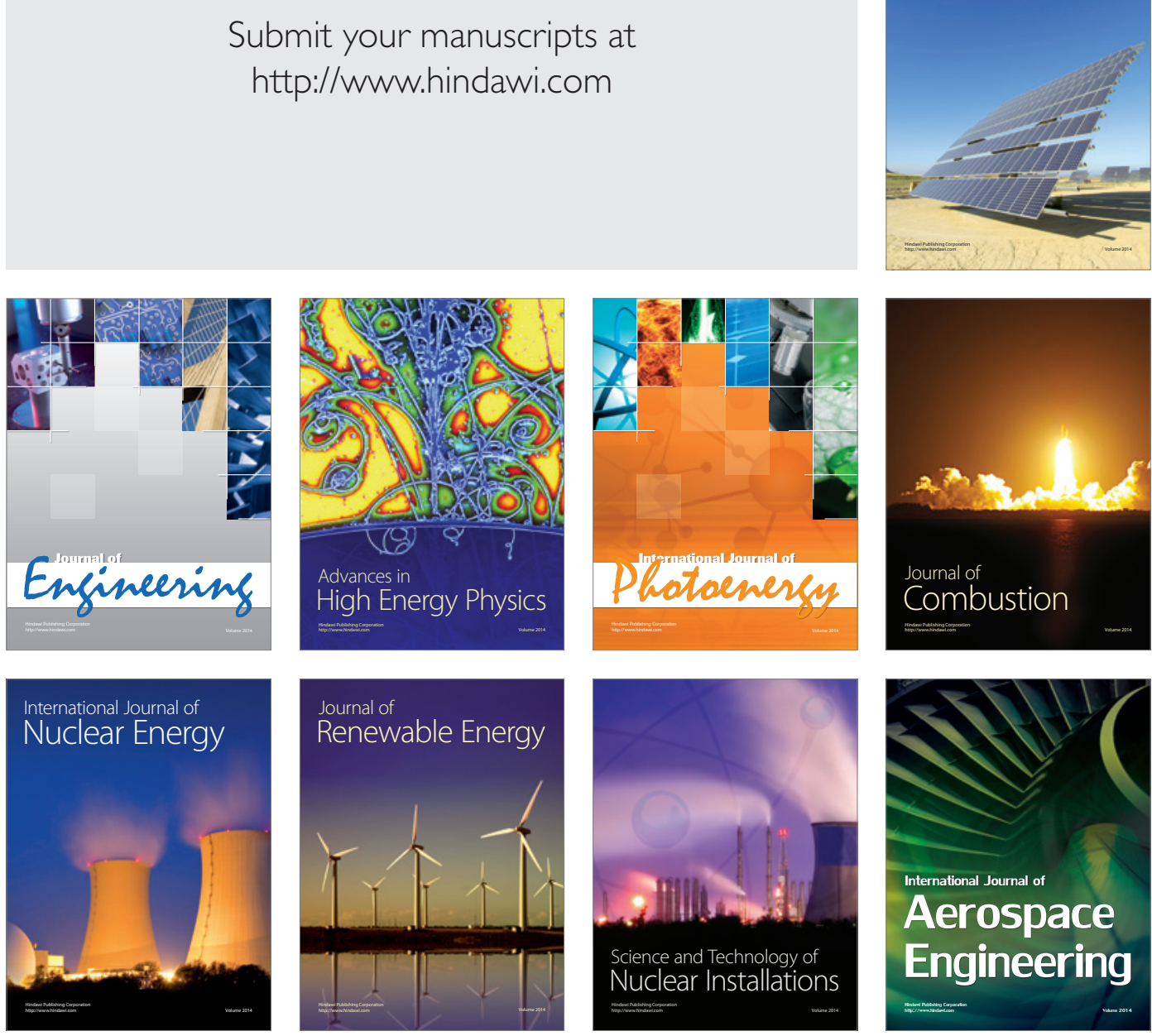